\title{
Autonomic Dysfunction in Major Depressive Disorder
}

\author{
Choudhury Rifat Jahan ${ }^{1}$, Shelina Begum ${ }^{2}$, Sultana Ferdousi ${ }^{3}$, Md. Moyeen Uddin ${ }^{4}$.
}

\begin{abstract}
Background: Cardiovascular (CV) morbidity is a major problem in patients suffering from depression as greater $\mathrm{CV}$ mortality is found in cardiac patients with depression. Objective: To assess cardiac autonomic nerve activity by power spectral analysis of heart rate variability in patients with Major Depressive disorder. Methods: This case control study was conducted in the Department of Physiology, Bangabandhu Sheikh Mujib Medical University (BSMMU), Shahbag, Dhaka during 2011. Sixty patients of both sexes with Major Depressive disorder (MDD) aged 20-50 years were enrolled. The patients were selected from the Department of Psychiatry in Bangabandhu Sheik Mujib Medical University (BSMMU). Thirty drug naive MDD patients and thirty medicated MDD patients were compared with 30 healthy control and also between them. The HRV parameters were recorded by 4 active channels, RMS Polyrite-D. For statistical analysis independent sample t-test test was used. Results: LF norm and LF/HF were significantly higher and Total power, HF power, HF norm were significantly lower in both drug naive and medicated MDD patients in comparison with those of healthy control. Conclusion: Autonomic nerve dysfunction involved both the drug naive and medicated MDD patients which was associated with higher sympathetic activity and reduced vagal modulation of the heart and sympathovagal imbalance. Antidepressent drug treatment did not have any effect on autonomic dysfunction.
\end{abstract}

Keywords: HRV, LF, HF, LF/HF Major depressive disorder.

Bangladesh Soc Physiol. 2014, June; 9(1): 37-41 For Authors Affiliation, see end of text.

http://www.banglajol.info/index.php/JBSP

\section{Introduction}

D epression is a common mental disorder that presents depressed mood, loss of interest or pleasure, feeling of guilt or low self worth, disturbed sleep or appetite, low energy and poor concentration ${ }^{1}$. The alarming rise of this disabling illness among world population turns it the second biggest global disease burden by 2020 after cardiovascular disease (CVD) ${ }^{2-3}$

It is further associated with diabetes mellitus, Alzeimer's disease, impaired lung function and cardiovascular disorders. Without apparent

Received Feb. 2014;

Accepted May 2014 cardiac involvement, high cardiovascular mortality were observed in depressive illness ${ }^{4}$.

Many symptoms of depression (e.g., dry mouth or constipation) are suggestive of autonomic involvement. The link between depression and autonomic dysfunction has drawn more attention since epidemiological studies have revealed that depressed patients have an increased risk of cardiovascular mortality and morbidity ${ }^{5}$.

Heart rate variability is a powerful tool for assessing intrinsic cardiac autonomic activity as

J Bangladesh Soc Physiol. 2014, June; 9(1): 37-41 
well as sympathovagal balance which represents interaction between cardiac sympathetic and parasympathetic activity ${ }^{6}$.

Power spectral components for HRV such as LF power LF norm represent sympathetic activity, HF power, HF norm for parasympathetic activity and $\mathrm{LF} / \mathrm{HF}$ ratio is an index of sympathovagal valance $^{7}$.

There are conflict of reports on results of low LF power, HF power and higher LF/HF both in medicated and drug naive depressed patients ${ }^{8}$.

There is intensive search to explore the relationship between autonomic dysfunction and its cardiovascular complication and Major Depressive Disorder (MDD). 4,8,9,10 .

Therefore, this study has been designed to evaluate the impact of depression on cardiac autonomic nerve function by power spectral analysis of HRV and compared the HRV parameters among drug naive MDD patients, medicated MDD patient and healthy control. The outcome of this study may alert the clinicians about the potential autonomic dysfunction and CVS complication in MDD.

\section{Methods}

This case control study was carried out to observe the HRV by frequency domain method in 60 major depressive patients of 20-50 years in the Department of Physiology, Bangabandhu Sheik Mujib Medical in 2011. 30 age and sex matched healthy subjects were selected as control. MDD patients were further subdivided into 30 drug naïve and 30 treated MDD patients with anti depressive drugs. The protocol was approved by the institutional review board of this university. The patients were selected from the Department of Psychiatry, BSMMU and the controls were selected among the Dhaka city dwellers. All the subjects were free from heart disease, hypertension, diabetes mellitus, chronic kidney disease, other psychiatric disorders, and smoking.

After selection, the subjects were thoroughly informed about the aim, objectives and the detail procedure of the study before examination and collection of blood sample. Informed written consent was taken from them. For examination the subjects were advised to have their meal by 9:00 pm on previous night, to remain free from any physical or mental stress, not to take any drugs affecting central nervous system and to have a restful sleep at night before the examination day. The subjects were advised to avoid tea or coffee at breakfast and to attend the Autonomic Nerve Function test Laboratory between 9.00 to 11.00 a.m. on the day of examination. Then the subject was interviewed and detail history regarding personal history, drug history, past medical history was taken to exclude exclusion criteria. Then thorough physical examinations and anthropometric measurement including height, weight, BMI were recorded in a data schedule. HRV data were recorded in a controlled laboratory environment. The subject was kept in complete bed rest in supine position for 15-20 minutes in a cool and calm environment. During this period subject was advised not to talk, eat or drink and also not to perform physical or any mental activity, even sleep. Then all preparations for recording of the Heart rate variability parameters were made by connecting the channels of ECG and a 5 minutes recording was taken in supine position. Data were obtained by software analysis of the power spectral band of the HRV. Data were expressed as mean $\pm \mathrm{SE}$. As test of significance, student's unpaired t-test, were employed. SPSS-16 version was used for data analysis.

\section{Results}

The demographic data are shown in figure 1

J Bangladesh Soc Physiol. 2014, June; 9(1): 37-41 
In drug naïve and medicated MDD patients, the mean values of TP, HF power, HF nu were found significantly $(\mathrm{p}<0.001)$ lower but LF/HF ratio and LF nu were significantly $(\mathrm{p}<0.001)$ higher compared to control. Again, no significant differences were observed when compared all these parameters between two groups of patients. (Table I) Correlation analysis of TP, HF power HF norm, LF power, LF norm \& LF/HF with duration of depression showed negative correlation but it was not statistically significant. Data are not presented here.

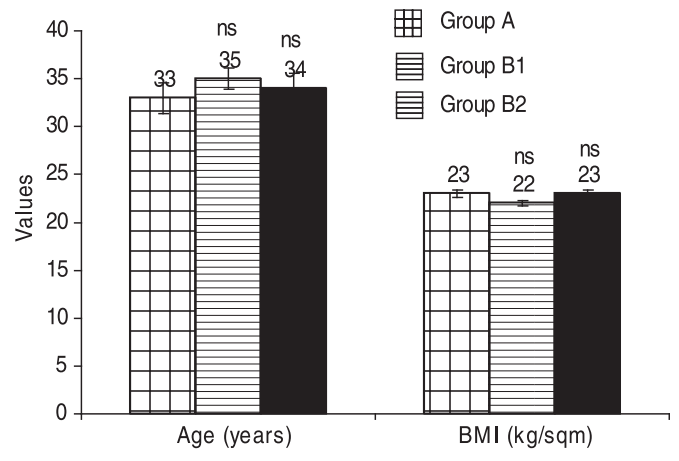

Figure 1: Age and BMI in different groups ( $\mathrm{n}=90)$ Data are expressed as mean and SE.

Group A(control), Group B1(Drug naïve) GroupB2 (Treated patients) All the groups were similar in respect of age and BMI

Table I: Power spectral measures of HRV in different groups $(\mathrm{n}=90)$

\begin{tabular}{lccc}
\hline HRV parameters & $\begin{array}{c}\text { Control } \\
(\mathrm{n}=30)\end{array}$ & $\begin{array}{c}\text { Drug naive patients } \\
(\mathrm{n}=30)\end{array}$ & $\begin{array}{c}\text { Drug treated patients } \\
(\mathrm{n}=30)\end{array}$ \\
\hline Total power $\left(\mathrm{ms}^{2}\right)$ & $2564.037 \pm 50.79$ & $1520.493 \pm 55.92^{* * * *}$ & $1507.405 \pm 58.99^{* * * *}$ \\
LF $\left(\mathrm{ms}^{2}\right)$ & $817.46 \pm 14.62$ & $858.03 \pm 22.60$ & $851.3 \pm 26.01$ \\
HF $\left(\mathrm{ms}^{2}\right)$ & $646.35 \pm 21.7$ & $255.7 \pm 14.51^{* * *}$ & $248.4 \pm 15.70^{* * *}$ \\
LF nu & $54.02 \pm .91$ & $80.97 \pm 1.26^{* * *}$ & $83.05 \pm 1.26^{* * *}$ \\
HF nu & $37.74 \pm 1.51$ & $25.56 \pm 2.43^{* * *}$ & $24.82 \pm 2.27^{* * *}$ \\
LF/HF & $1.41 \pm 0.05$ & $3.89 \pm .34^{* * *}$ & $3.76 \pm .35^{* * *}$ \\
\hline
\end{tabular}

Data were expressed as Mean \pm SE. Statistical analysis were done by Independent sample t-test $\mathrm{LF}=$ Low frequency. $\mathrm{HF}=$ High frequency. $\mathrm{LF}(\mathrm{nu})=$ Low frequency in normalized unit. $\mathrm{HF}(\mathrm{nu})=$ High frequency in normalized unit. LF/HF $=$ Ratio of low frequency and high frequency. $\mathrm{ms}^{2}=$ squared milisecond. ${ }^{\wedge} * * * \mathrm{p}<0.01$ control vs patients

\section{Discussion}

The present study observed the power spectral parameter of HRV in patients with Major Depressive Disorder to assess their cardiac autonomic nervous activity. The values of all the spectral parameters in healthy control were almost similar and also with findings, reported by various investigators. ${ }^{11-13}$

In this study, significantly lower total power, HF power and HF norm and significantly higher LF norm in both drug naive and medicated depressed patients compared to control suggest lower parasympathetic and higher sympathetic drive and higher LH/HF ratio as index of sympathovagal imbalance in MDD patients. Similar observations were also made by some researchers ${ }^{8,16-17}$. Several other researchers observed similar trends but it was not statistically significant . ${ }^{9,11,12}$ Opposite findings were also found in some literature ${ }^{8,9,11}$ 
In this study no significant difference were observed in these parameters when compared between drug naïve and medicated MDD patients. This finding also suggest autonomic dysfunction in MDD patients remained unaffected by treatment with anti depressive drug.

Research results showed that major depressive disorder is associated with higher sympathetic and lower parasympathetic activity but specific CNS mechanism for altered autonomic activity in depression is not clearly understood. ${ }^{8.13,14} 16,17$

There is evidence that hyperactivity of $\mathrm{CRH}$ containing neuron in hypothalamas stimulates several autonomic centers which in turn results in increased peripheral sympathetic activity ${ }^{18}$.

Moreover, reduced monoamine in CNS leads to depleted central norepinephrine (NE) store resulting in depression. Therefore, low CNS NE activity would cause withdrawl of á receptor mediated inhibitory effect on peripheral sympathetic outflow ${ }^{18}$.

In the present study, finding of the autonomic dysfunction characterized by increased sympathetic and reduced parasympathetic and symapthovagal imbalance state in depressed patient may be linked to this CNS mechanism. Further more, antidepressent drug could not bring any improvement of this disorder though most of the typical anti depressant drugs usually works by inhibiting MAO thus tends to restore NE level ${ }^{19}$.

\section{Conclusion}

This study concluded that autonomic dysfunction associated with markedly decreased parasympathetic, increased sympathetic and sympathovagal imbalance with increased sympathetic dominance occured in MDD patients. Antidepressive drug treatment could not improve autonomic impairment in Major depression.

\section{Author affiliations}

1. Choudhury Rifat Jahan, Assistant Professor, Department of Physiology, Sylhet Womens Medical College, Mirboxtulla, Sylhet. Email:rifatziyad@gmail.com.

2. Shelina Begum, Professor, Chairman, Department of Physiology, Bangabandhu Sheikh Mujib Medical University(BSMMU), Bangladesh. Email: shelina1982@gmail.com.

3. Sultana Ferdousi,Associate Professor, Department of Physiology, Bangabandhu Sheikh Mujib Medical University(BSMMU), Bangladesh. Email: sferdousiratna@gmail.com.

4. Md.Moyeen Uddin, Assistant Professor, Medicine, Sylhet Osmani Medical College .Email: umoyeen@email.com

\section{References}

1. WHO Mental health.[internet].2011[cited 2011 June 6]. Available from: http:// www. who. int/ mental_health/ management/depression/ definition.

2. Kleiger RE, Stein PK, Bosner MS, Rottman JN. Time domain measurements of heart rate variability. Cardiol Clin. 1992; 10(3): 487-498.

3. Muhit MA, Maruf MM,Ahmed H, Alam MT.Depression and physical illness:an update. Ban Med J.2011; 40(1):53-57.

4. Kim CK, Bartholomew BA, Marsh M, Dicken T, Smoller SW, Curb D, Oberman A, Hsia J, Gardin J, Wong ND, Barton B, McMahan, Sheps DS. Depressive Symptoms and HRV in postmenopausal women. Arch Intern Med. 2005; 165:1239-1244.

5. Rabins PV, Harvis K, Koven S. High fatality rates of late life depression associated with cardiovascular disease. J Affect Disord. 1985; 9: 165-167.

6. Kemp AH, Quintana DS, Gray MA, Felmingham KL, Brown K, Gatt JM. Impact of Depression and antidressant treatment on heart rate variability: A review and meta analysis. Biol Psychiatry. 2010; 67: 1067-1074

7. Task Force of the European society of cardiology and the North American society of pacing and electrophysiology, Heart Rate Variability. standards of measurement, physiological interpretation and clinical use. Circulation. 1996; 93: 1043-1065.

J Bangladesh Soc Physiol. 2014, June; 9(1): 37-41 
8. Udupa K, Sathyaprabha TN, Thirthalli J, Kishore KR, Lavekar GS, Raju TR, Gangadhar BN. Alteration of cardiac autonomic functions in patients with major depression: A study using heart rate variability measures. J Affect disord. 2007; 100: 137-141.

9. Agelink MW,Boz H,Andrich J.Relationship between major depression and heart rate variability. Clinical consequences and implications for antidepressive treatment. Psychiatry res.2002; 113:139-149.

10. Nashoni E, Aravot D, Aizenberg D, Sigler M, Zalsman G, Strasberg B, Imbar S, Weizman A. Heart rate variability in patients with major depression. Psychosomatics. 2004; 45: 129-134.

11. Jahan K, Begum N,Ferdousi S.Power spectral analysis of heart rate variability in female Rheumatoid Arthritis patients. J Bangladesh soc Physiol. 2012; 7(1):8-12

12. Nayem M, Begum N, Ferdousi S. Assessment of Autonomic nerve function in patients with irritable bowel syndrome. J Bangladesh soc Physiol. 2012; 7(1):53-59.

13. Tabassum R, Begum N, Ferdousi S, Begum S, Ali T. Power spectral analysis of heart rate variability in hypertensive male.

14. Kooy KGVD, Hout HPJV, Marwijk HWJV, Hann MD, Stehouwer CDA, Beekman ATF. Differences in heart rate variability between depressed and non depressed elderly. Int J Geriatr Psychiatry. 2006; $21: 147-150$

15. Bar KJ, Greiner W, Jochum T, Friedrich M, Wagner $\mathrm{G}$, Sauer $\mathrm{H}$. The influence of major depression and its treatment on heart rate variability and a pupillary light reflex parameters. J Affec Disord. 2004; 82: 245-252.

16. Guinjoan SM, Bernabo JL, Cardinali DP. Cardiovascular tests of autonomic function and sympathetic skin responses in patients with major depression. J Neurol Neurosurg Psychiatry. 1995; 58: 299-302.

17. Koschke M, Boettger MK, Schulz S, Berger S,Terhaar J, Voss A, Yeragani VK, Bär KJ. Autonomy of autonomic dysfunction in major depression. Psychosom Med. 2009; 71: 852-860.

18. Veith RC, Lewis $\mathrm{N}$, Linares OA, Barnes RF, Raskind MA,Villacres EC, Murburg MM, Ashleigh EA, Castillo S, Peskind ER, Pascualy M, Halter JB. Sympathetic nervous system activity in Major Depression. Arch Gen Psychiatry. 1994; 51: 411-422.

19. Barret KE, Barman SM, Boitano S and Brooks HL. Ganong,s review of medical Physiology.24 ${ }^{\text {th }}$ ed.New Delhi :Tata MacGraw-Hill company;2012.p149. 